\title{
Correlation between the BANA Test and Oral Malodor Parameters
}

\author{
A. Kozlovsky 1, , D. Gordon ${ }^{1}$, I. Gelernter ${ }^{3}$, W.J. Loesche ${ }^{4}$, and M. Rosenberg ${ }^{1,2}$
}

${ }^{1}$ The Maurice and Gabriela Goldschleger School of Dental Medicine and the 2Department of Human Microbiology, Sackler Faculty of

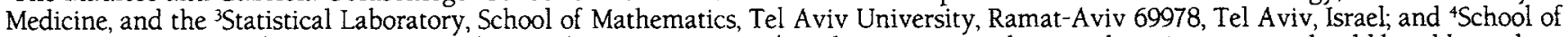
Dentistry, University of Michigan, Ann Arbor, Michigan 48109, USA; * to whom correspondence and reprint requests should be addressed

\begin{abstract}
The purpose of the present investigation was to test the association between the BANA test (Perioscan ${ }^{\circledast}$, Oral-B), and oral malodor parameters. The subject population consisted of 52 Israeli adults, 43 of whom complained of oral malodor. Oral malodor measurements consisted of peak and steady-state volatile sulphide measurement by a portable sulphide monitor (Interscan Corp., model 1170), as well as organoleptic measurements of malodor from whole mouth, tongue, and saliva. Samples for the BANA test were obtained from four loci (shallow pocket, deep pocket, tongue dorsum, saliva); results were scored as negative (0), weak ( 1 ), or strong (2). BANA scores were significantly associated with odor-judge ratings, with the highest association obtained when BANA saliva scores and odor-judge saliva assessment were compared $(r=0.500 ; p<$ 0.001 ). BANA tests from the different loci were not significantly associated with sulphide monitor levels. Stepwise multiple-regression analysis of odor-judge measurements in terms of sulphide levels and average BANA scores showed that both log peak sulphide levels as well as BANA scores were significantly factored into the equations, yielding, in all cases, highly significant correlations (multiple $r=0.57,0.50$, and 0.59 , respectively, with significance levels of $0.0001,0.001$, and $<0.0001$, for whole mouth, tongue, and saliva malodor, respectively). The results suggest that the BANA scores are associated with a component of oral malodor which is independent of volatile sulphide measurements and suggest its use as an adjunct test to volatile sulphide measurement.
\end{abstract}

Key words. Diagnostic Tests, Halitosis, Periodontal Diseases, Porphyromonas gingivalis, Treponema denticola.

Received May 26, 1993; Accepted December 10, 1993

\section{Introduction}

Oral malodor (also known as bad breath, halitosis, fetor ex ore) usually originates when the halitus emitted through the mouth combines with malodorous volatile compounds originating in the oral cavity (Tonzetich, 1977). Tonzetich and Richter (1964) were the first to report that oral malodor is primarily associated with volatile sulphur compounds (VSC), rather than with amines and ammonia. VSC are produced in the oral cavity through the putrefactive action of micro-organisms on exogenous and endogenous proteinaceous substrates, including exfoliated cells, leukocytes, saliva, blood, and food debris (Tonzetich and Kestenbaum, 1969; Tonzetich, 1977). The most popular method for instrumental analysis of VSC has been gas chromatography (GC) (Tonzetich, 1971). More recently, a portable sulphide monitor has been proposed for the rapid chairside measurement of overall sulphide levels (Rosenberg et al., 199la,b). Quantitative measurement is of ten accompanied by hedonic (organoleptic) measurement by one or more odor judges (Rosenberg and McCulloch, 1992). Both quantitative techniques of gas analysis have been shown to be significantly correlated to hedonic measurements (Schmidt et al., 1978; Rosenberg et al., 199la,b). Subjects with periodontal disease frequently suffer from oral malodor (Tonzetich, 1973; Tonzetich and Ng, 1976), and positive correlations have been demonstrated between the severity of periodontitis and VSC levels in mouth air (Tonzetich and McBride, 1981; Yaegaki and Sanada, 1992) as well as in pockets (Rizzo, 1967; Coil and Tonzetich, 1985; Mardinger et al., 1992). Many oral bacteria, including those isolated from deep periodontal pockets, are capable of producing VSC, primarily hydrogen sulfide and methyl mercaptan, from serum and from L-cysteine and Lmethionine (Persson et al., 1990). 
Three of the bacterial species associated with periodontitis-Porphyromonas gingivalis (Loesche et al., 1985), Treponema denticola (Moore et al., 1985; Simonson et al., 1988), and Bacteroides forsythus (Dzink et al., 1988)-are among the most active hydrogen sulphide producers in vitro (Persson et al., 1990). The presence of these organisms in dental plaque can be demonstrated based on their ability to hydrolyze the synthetic trypsin substrate $\mathrm{N}$-benzoyl-DLarginine-2-naphthylamine (BANA; Laughon et al., 1982; Tanner et al., 1985; Loesche, 1986; Loesche et al., 1987).

The purpose of the present investigation was to examine the relationship between the presence of periodontopathic micro-organisms in dental plaque, tongue scrapings, and saliva, as measured by the BANA assay, with instrumental and organoleptic measurements related to oral malodor.

\section{Materials and methods}

\section{Patient population}

The study consisted of 52 patients (mean age, $37.9 \pm 11.9$ years; 35 females), ranging from 11 to 63 years old. Among the subjects, 43 complained of bad breath, having responded to a newspaper article on the subject. Exclusion criteria included smokers, subjects suffering from systemic disease or taking antibiotics, and denture wearers. The study included parameters not reported here, including salivary cadaverine levels (Goldberg et al., 1994), as well as tests of self-estimation of oral malodor, and psychological data (in preparation)

On the day of the examination, the participants were instructed to refrain from using scented personal products Subjects were also requested to refrain from oral activities, including drinking, eating, chewing gum, and mouthrinsing two hours prior to appointment. Measurements were obtained on three dates within over a 12-day period.

\section{Clinical examination}

All the participants were scored for plaque accumulation and gingival health of all tooth surfaces (including wisdom teeth) by the Plaque Index (PI; Silness and Loe, 1964) and Gingival Index (GI; Löe and Silness, 1963). Probing depth measurements were recorded on days 2 and 3 of the study $(\mathrm{N}=30)$ with a Michigan O probe, at six reference loci on the buccal and lingual sides of each tooth, including wisdom teeth. All participants were subjected to whole-mouth probing so that shallow and deep pockets could be identified for BANA sampling.

\section{BANA assay}

The BANA reagent card (Perioscan ${ }^{\circledR}$, Oral-B Laboratories, Redwood City, CA; Loesche et al., 1990a,b) was used according to manufacturer's instructions. Results were recorded as either: strong, dark blue spots (score $=2$ ); weak, light blue spots ( score $=1$ ); or no color change $($ score $=0$ ).
Subgingival plaque was removed by curette from a tooth presenting a shallow pocket $(<4 \mathrm{~mm})$ and one presenting a deep pocket ( $\geq 4 \mathrm{~mm}$ ), following local supragingival plaque removal. Subgingival plaque samples were then deposited directly onto the reagent card. Tongue samples were obtained by scrapings from the posterior tongue dorsum, obtained by means of a disposable plastic blade, and applied directly onto the reagent card. Saliva samples were taken following the dental examination by asking the subjects to expectorate into a Petri dish. Aliquots (ca. $10 \mu \mathrm{L}$ ) of expectorated saliva were immediately applied to the reagent card. The same sample expectorates were subsequently used for odor-judge measurements (below).

\section{Volatile Sulphide Concentrations}

VSC measurements were made by use of a portable industrial sulphide monitor (model 1170, 0.5 ppm full-scale, Interscan Corp., Chatsworth, CA), zeroed on ambient air before each measurement. A disposable $6.5-\mathrm{mm}^{-}$ circumference plastic straw was inserted into the air inlet of the monitor. Each patient was instructed to bring his/her slightly opened mouth over the straw so that it extended approximately $4 \mathrm{~cm}$ into the oral cavity, and to breathe through the nose during the measurement. Both peak (maximum) and steady-state levels attained were determined in parts per billion (ppb) sulphide equivalents.

\section{Odor-judge assessment}

Organoleptic assessment was made by an odor judge (M.R.) whose organoleptic scores have been shown to correlate with those of other judges, as well as volatile sulphide levels, in previous studies (Rosenberg et al., 1991a,b). Organoleptic malodor scores were recorded on a continuous unmarked 10-cm scale, marked at both ends as no odor and maximal odor, respectively. Results were scored independently for (i) whole mouth malodor, (ii) tongue malodor, and (iii) saliva malodor. For measurement of whole-mouth malodor, subjects were requested to breathe out from the mouth at $c a$. $10 \mathrm{~cm}$ from the nose of the judge. For measurement of tongue malodor, the subjects were instructed to extend their tongue and lick their wrist in a perpendicular fashion. The odor judge assessed the odor from a distance of ca. $3 \mathrm{~cm}$, following $5 \mathrm{~s}$. For measurement of saliva malodor, the subjects were asked to expectorate into Petri dishes, which were incubated for approximately $5 \mathrm{~min}$ at $37^{\circ} \mathrm{C}$, and then assessed at a distance of $\mathrm{ca} .4 \mathrm{~cm}$ from the nose of the odor judge. Expectoration was carried out post-probing in order to potentiate saliva odor levels. VSC and malodor measurements were carried out following the dental examination.

\section{Statistical analyses}

Pearson and Spearman correlation coefficients were used as indicated. ANOVA was used to test for differences in log VSC scores over the three days of the study. To test for 
Table 1. Frequency distribution of BANA scores

\begin{tabular}{lccc}
\hline Site & Negative & Weak-positive & Strong-positive \\
\hline Shallow Pocket & $3^{2}$ & 29 & 20 \\
Deep Pocket & 2 & 20 & 30 \\
Tongue & 27 & 22 & 3 \\
Saliva & 33 & 15 & 4 \\
\hline
\end{tabular}

a Number of samples.

differences between males and females, the unpaired $t$ test was used.

\section{Results}

Table 1 presents the distribution of BANA scores from the four loci examined. Shallow and deep pockets yielded high scores, with 30 and 20 strongly positive results, respectively, as opposed to only 3 and 2 negative scores, respectively. In contrast, 27 and 33 samples taken from tongue dorsa and from saliva, respectively, were negative. In all instances, significant correlations ( $\mathrm{p} \leq 0.005$; Spearman) were found when BANA scores were compared among subjects. The highest association was between BANA tongue vs. saliva scores $(\mathrm{r}=0.589 ; \mathrm{p}<0.001)$. Shallow pocket levels appeared to be more highly related to tongue scores $(r=0.548 ; p<$ 0.001 ), whereas deep pocket scores were more highly associated with saliva results $(r=0.561 ; p<0.001)$. In order to obtain a wider overall distribution, the average score of the four BANA tests was calculated for each subject (Fig.).

Table 2 presents the mean \pm standard deviation for the dental parameters and malodor measurements. Transformation of peak and steady-state VSC measurements to natural logarithms was carried out in order to obtain near-normal distributions. Among the three

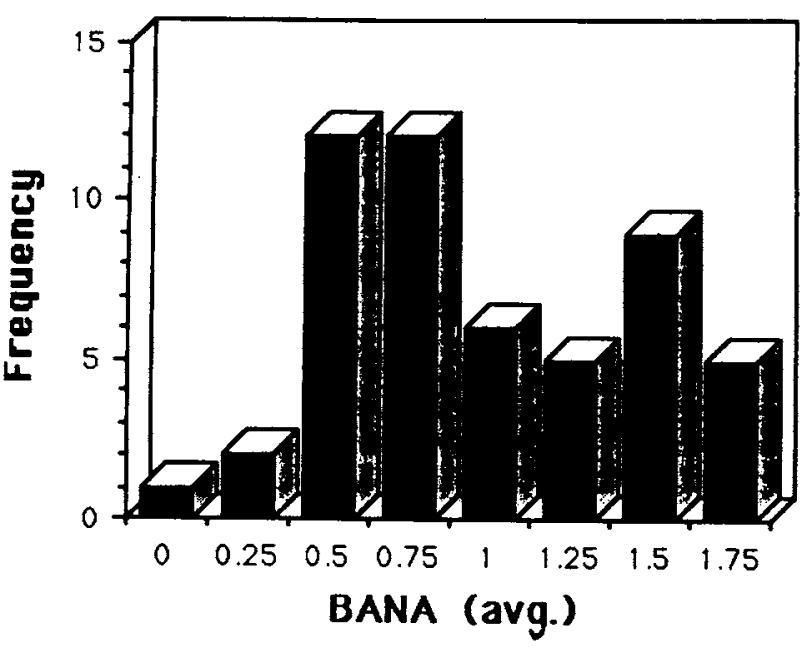

Figure. Frequency distribution of mean BANA scores.

organoleptic measurements, whole mouth odor scores were generally higher than saliva and tongue odor assessments (Table 2). Among the various measurements, the only significant difference between males $(\mathrm{N}=17)$ and females $(\mathrm{N}=35)$ was in mean BANA saliva scores $(0.772 \pm 0.187$ for males, as opposed to $0.530 \pm 0.090$ for females, $p=0.037$ ). No significant decrease was observed in mean peak of steadystate VSC measurements over the three days of the study ( $p$ $>0.05$, ANOVA). Similarly, the time of day of measurement was not significantly related to any of the parameters.

The comparison between BANA scores and both oral malodor and dental parameters is summarized in Table 3. Associations with peak and steady-state VSC measurements were, for the most part, not significant. Only in the comparison of average BANA scores with steady-state

Table 2. Dental parameters and malodor measurements

\begin{tabular}{|c|c|c|}
\hline Measurement & Mean \pm Standard Deviation & No. of Observations \\
\hline Plaque Index (PI) & $1.2 \pm 0.5$ & 52 \\
\hline Gingival Index (GI) & $1.1 \pm 0.4$ & 52 \\
\hline Mean Probing Depth & $2.9 \pm 0.7 \mathrm{~mm}$ & 30 \\
\hline BANA (shallow pocket) & $1.3 \pm 0.6$ & 52 \\
\hline BANA (deep pocket) & $1.5 \pm 0.6$ & 52 \\
\hline BANA (tongue dorsum) & $0.5 \pm 0.6$ & 52 \\
\hline BANA (saliva) & $0.4 \pm 0.6$ & 52 \\
\hline BANA (average) & $1.0 \pm 0.5$ & 52 \\
\hline Peak VSC & $155 \pm 62 \mathrm{ppb}$ & 51 \\
\hline Steady-state VSC & $103 \pm 38 \mathrm{ppb}$ & 51 \\
\hline Log Peak VSC & $2.2 \pm 0.14$ & 51 \\
\hline Log Steady-state VSC & $2.0 \pm 0.14$ & 51 \\
\hline Whole mouth odor (odor judge) & $4.3 \pm 2.0$ & 52 \\
\hline Tongue odor (odor judge) & $2.5 \pm 1.3$ & 52 \\
\hline Saliva odor (odor judge) & $3.4 \pm 2.5$ & 52 \\
\hline
\end{tabular}


Table 3. Spearman Correlation Coefficients comparing BANA results with oral malodor and dental parameters

\begin{tabular}{|c|c|c|c|c|c|}
\hline & $\begin{array}{c}\text { BANA } \\
\text { (Shallow Pocket) }\end{array}$ & $\begin{array}{c}\text { BANA } \\
\text { (Deep Pocket) }\end{array}$ & $\begin{array}{c}\text { BANA } \\
\text { (Tongue) }\end{array}$ & $\begin{array}{l}\text { BANA } \\
\text { (Saliva) }\end{array}$ & $\begin{array}{l}\text { BANA } \\
\text { (Avg.) }\end{array}$ \\
\hline \multirow[t]{2}{*}{ Log Peak VSC } & $r=-0.019$ & 0.151 & 0.134 & 0.059 & 0.098 \\
\hline & $p=0.894$ & 0.290 & 0.349 & 0.679 & 0.493 \\
\hline \multirow[t]{2}{*}{ Log Steady-state VSC } & 0.209 & 0.263 & 0.255 & 0.245 & 0.304 \\
\hline & 0.142 & 0.063 & 0.071 & 0.083 & 0.030 \\
\hline Whole mouth & 0.332 & 0.259 & 0.364 & 0.359 & 0.399 \\
\hline (odor judge) & 0.016 & 0.034 & 0.008 & 0.009 & 0.003 \\
\hline Tongue & 0.260 & 0.331 & 0.271 & 0.372 & 0.373 \\
\hline (odor judge) & 0.063 & 0.017 & 0.052 & 0.007 & 0.006 \\
\hline Saliva & 0.399 & 0.312 & 0.338 & 0.500 & 0.455 \\
\hline (odor judge) & 0.003 & 0.025 & 0.014 & $<0.001$ & 0.001 \\
\hline \multirow[t]{2}{*}{ PI } & 0.325 & 0.101 & 0.293 & 0.329 & 0.306 \\
\hline & 0.019 & 0.476 & 0.035 & 0.017 & 0.028 \\
\hline \multirow[t]{2}{*}{ GI } & 0.452 & 0.282 & 0.481 & 0.406 & 0.472 \\
\hline & 0.001 & 0.043 & $<0.001$ & 0.003 & $<0.001$ \\
\hline \multirow[t]{2}{*}{ Mean Probing Depth } & 0.491 & 0.284 & 0.326 & 0.551 & 0.514 \\
\hline & 0.006 & 0.129 & 0.079 & 0.002 & 0.004 \\
\hline
\end{tabular}

measurements was a significant association $(r=0.304, p=$ 0.030 ) obtained. In contrast, organoleptic ratings of whole mouth, tongue, and saliva malodor were generally associated with BANA results. The highest association was found for BANA saliva scores $v$ s. saliva malodor $(r=0.500 ; p$ $<0.001$ ). Average BANA scores were highly associated ( $\mathrm{p} \leq$ $0.006)$ with all three organoleptic ratings. When BANA scores were compared with GI, highly significant correlations $(\mathrm{p} \leq 0.001)$ were found for BANA average, BANA shallow pocket, and BANA tongue. Probing depth was highly associated with BANA shallow pocket $(p=$ $0.006)$, BANA average $(p=0.004)$, and BANA saliva $(p=$ 0.002 ) scores. Deep pocket BANA scores were not significantly associated with PI or probing depth.

Table 4 presents Pearson correlation coefficients comparing the oral-malodor-associated results as well as dental parameters. Among the dental parameters, GI scores provided the highest correlations with all odor-judge measurements ( $p \leq$ 0.001). PI values were highly associated with GI, probing depth, and odor-judge saliva scores ( $p \leq 0.001$ ), but not with sulphide measurements. Correlations between GI and peak sulphide levels were higher than between GI and steady-state sulphide values $(p=0.017$ and $p=0.053$, respectively). Probing depth scores were more highly associated with steady-state than with peak sulphide scores $(\mathrm{p}=0.008$ and $\mathrm{p}=0.050$, respectively). All odor-judge parameters were highly associated with one another $(\mathrm{p}<0.001)$. Correlations between both peak and steady-state sulphide scores vs. odor-judge ratings of whole mouth and saliva were highly associated $(\mathrm{p}<0.001)$. Correlations between peak and steady-state sulphide scores and odor-judge tongue malodor scores were slightly lower $(p=0.003$ and $p=0.013$, respectively).

In an attempt to relate each of the three odor-judge measurements to both VSC levels and BANA (avg.) scores, step-wise forward multiple-regression analysis was carried out (Table 5). In all three cases (whole mouth, tongue, and saliva), both log peak monitor levels and BANA (avg.) scores factored into the equations, yielding, in all cases, highly significant correlations (multiple $r=0.568,0.501$, and 0.586 , respectively, with significance levels of $p=0.0001, p=0.001$, and $p<0.0001$, respectively). Following entry of log peak monitor levels into the regression equation, steady-state levels did not contribute significantly and were not entered.

\section{Discussion}

The Perioscan ${ }^{\otimes}$ BANA assay is a user-friendly chairside technique which has previously been shown to correlate with the levels of three specific oral microbial species whose presence reflects periodontal disease activity (Loesche, 1986; Loesche et al., 1990a,b; Schmidt et al., 1988). The results presented here provide further support for previously demonstrated associations between BANA test results and periodontal parameters (e.g., GI, probing depth). Among the sites tested here, deep pocket BANA samples generally yielded less significant associations with dental parameters than BANA samples obtained from the other three sites. This may be associated with the low number $(n=2)$ of deep pocket samples which gave negative results, in agreement with previous data suggesting relatively low specificity (Loesche et al., 1990b) of the BANA assay when plaque samples were compared with dental parameters. Results suggest that the BANA status of a single deep pocket may not be representative of parameters involving overall status.

The present study provides initial data comparing BANA scores with oral malodor parameters. Of considerable 
Table 4. Pearson Correlation Coefficients comparing oral malodor-associated results and dental parameters

\begin{tabular}{|c|c|c|c|c|c|c|c|c|}
\hline & PI & GI & $\begin{array}{l}\text { Mean Probing } \\
\text { Depth }\end{array}$ & $\begin{array}{l}\text { Whole Mouth } \\
\text { (odor judge) }\end{array}$ & $\begin{array}{l}\text { Tongue } \\
\text { (odor judge) }\end{array}$ & $\begin{array}{l}\text { Saliva } \\
\text { (odor judge) }\end{array}$ & $\begin{array}{l}\text { Log Peak } \\
\text { VSC }\end{array}$ & $\begin{array}{l}\text { Log Steady- } \\
\text { state VSC }\end{array}$ \\
\hline PI & $\begin{array}{l}r=1.00 \\
p=0.000\end{array}$ & & & & & & & \\
\hline GI & $\begin{array}{r}0.813 \\
<0.001\end{array}$ & 1.00 & & & & & & \\
\hline $\begin{array}{l}\text { Mean probing } \\
\text { depth }\end{array}$ & $\begin{array}{r}0.577 \\
<0.001\end{array}$ & $\begin{array}{r}0.668 \\
<0.001\end{array}$ & 1.00 & & & & & \\
\hline $\begin{array}{l}\text { Whole mouth } \\
\text { (odor judge) }\end{array}$ & $\begin{array}{l}0.383 \\
0.003\end{array}$ & $\begin{array}{r}0.536 \\
<0.001\end{array}$ & $\begin{array}{r}0.581 \\
<0.001\end{array}$ & 1.00 & & & & \\
\hline $\begin{array}{l}\text { Tongue } \\
\quad \text { (odor judge) }\end{array}$ & $\begin{array}{l}0.383 \\
0.003\end{array}$ & $\begin{array}{r}0.468 \\
<0.001\end{array}$ & $\begin{array}{l}0.466 \\
0.005\end{array}$ & $\begin{array}{r}0.725 \\
<0.001\end{array}$ & 1.00 & & & \\
\hline $\begin{array}{l}\text { Saliva } \\
\quad \text { (odor judge) }\end{array}$ & $\begin{array}{l}0.433 \\
0.001\end{array}$ & $\begin{array}{r}0.583 \\
<0.001\end{array}$ & $\begin{array}{l}0.513 \\
0.002\end{array}$ & $\begin{array}{r}0.730 \\
<0.001\end{array}$ & $\begin{array}{r}0.599 \\
<0.001\end{array}$ & 1.00 & & \\
\hline Log peak VSC & $\begin{array}{l}0.188 \\
0.093\end{array}$ & $\begin{array}{l}0.298 \\
0.017\end{array}$ & $\begin{array}{l}0.305 \\
0.050\end{array}$ & $\begin{array}{r}0.472 \\
<0.001\end{array}$ & $\begin{array}{l}0.381 \\
0.003\end{array}$ & $\begin{array}{l}0.439 \\
0.001\end{array}$ & 1.00 & \\
\hline $\begin{array}{l}\text { Log steady-state } \\
\text { VSC }\end{array}$ & $\begin{array}{l}0.092 \\
0.261\end{array}$ & $\begin{array}{l}0.230 \\
0.053\end{array}$ & $\begin{array}{l}0.436 \\
0.008\end{array}$ & $\begin{array}{l}0.404 \\
0.002\end{array}$ & $\begin{array}{l}0.313 \\
0.013\end{array}$ & $\begin{array}{l}0.413 \\
0.001\end{array}$ & $\begin{array}{r}0.718 \\
<0.001\end{array}$ & 1.00 \\
\hline
\end{tabular}

interest is the finding that BANA results, although significantly associated in most cases with odor-judge ratings, were generally poorly associated with VSC levels. When multiple-regression analysis was performed with odor-judge measurements as the dependent variable, both peak VSC levels and BANA scores factored into the regression, yielding highly significant associations. These findings suggest that BANA scores are associated with some other factor(s), which helps account for odor-judge assessment of oral malodor, exclusive of VSC data. Possibly, micro-organisms associated with BANA assay contribute additional non-sulphide odorants, such as cadaverine (Goldberg et al.,1994), to the oral halitus.

In the present study, highly significant correlations were found for odor-judge scores as compared with dental parameters. Correlations between dental parameters and malodor levels have been shown in most previous studies (Rizzo, 1967; Tonzetich, 1973, 1977; Tonzetich and McBride,
1981; Coil and Tonzetich, 1985; Rosenberg et al., 1991a; Mardinger et al., 1992; Yaegaki and Sanada, 1992). The most striking associations obtained here were: (i) whole mouth odor assessment, as compared with mean probing depth $(\mathrm{r}=$ $0.581 ; \mathrm{p}<0.001$ ); and (ii) saliva odor assessment, as compared with GI ( $r=0.583 ; \mathrm{p}<0.001)$. It should be emphasized that, in the present study, saliva samples were collected following probing (even in those cases in which average probing depth was not recorded, probing was performed to assess deep vs. shallow pockets). The introduction of subgingival components into the saliva samples may have contributed to the highly significant correlations found with parameters involving saliva.

Quantification of oral malodor is a problem which has delayed scientific investigations into its causes and treatments. Oral malodor measurement by multiple judges is cumbersome and introduces problems of subjectivity and reproducibility. Agreement among judges, while highly significant, is usually

Table 5. Stepwise multiple-regression analysis of odor-judge assessments in terms of VSC and BANA (Avg.) scores

\begin{tabular}{lccccc}
\hline & & \multicolumn{3}{c}{ Coefficient for } \\
\cline { 3 - 4 } $\begin{array}{l}\text { Dependent } \\
\text { Variable }\end{array}$ & Intercept & $\begin{array}{c}\text { Log Peak } \\
\text { VSC }\end{array}$ & $\begin{array}{c}\text { Log Steady- } \\
\text { state VSC }\end{array}$ & BANA (avg.) & Multipler \\
\hline Whole mouth & -6.845 & 5.820 & N.E. & 0.333 & 0.568 \\
& $0.016^{b}$ & 0.001 & 0.684 & 0.010 & 0.0001 \\
Tongue & -3.24 & 2.90 & N.E. & 0.217 & 0.501 \\
& 0.082 & 0.010 & 0.460 & 0.012 & 0.001 \\
Saliva & -9.648 & 6.533 & N.S. & 0.507 & 0.585 \\
& 0.006 & 0.002 & 0.796 & 0.002 & $<0.0001$ \\
\hline
\end{tabular}

a Not entered into the equation due to lack of significance.

b Numbers in italics represent levels of significance. 
moderate (Rosenberg et al., 1991a,b; Rosenberg and McCulloch, 1992). One major difficulty is that once a subject has expelled breath for estimation by one judge, the halitus emitted subsequently for other judge(s) may differ in intensity and composition (Rosenberg and McCulloch, 1992). Intra-oral measurements with the sulphide monitor provide rapid quantitative data which are reproducible and sensitive, easy-to-use, and relatively inexpensive. Peak and steady-state sulphide monitor levels have been previously shown to provide highly significant correlations with odorjudge measurements (Rosenberg et al., 1991a,b, 1992) but cannot be inferred to be a "gold standard" for bad breath measurement and thus to replace organoleptic assessment (Rosenberg and McCulloch, 1992). We have previously proposed that clinical measurement of oral malodor be conducted by organoleptic examination of oral malodor deriving from several loci, in conjunction with sulphide monitor measurements, as well as dental assessment (Rosenberg et al., 1991a). The results of the present study suggest that the BANA test may be a simple, adjunct assay together with volatile sulphide determination in order to provide additional quantitative data which contribute to the overall association with odor-judge estimation. These techniques may prove advantageous in facilitating comparison of oral malodor investigations conducted at different locations by various investigators.

\section{Acknowledgments}

This investigation was carried out in the Alpha Omega Laboratories. We thank C.A.G. McCulloch for valuable comments and discussions related to the study, and Yardena Mazor for excellent technical assistance. We are grateful to G. Pitts, Oral-B Laboratories, for advice and provision of Perioscan $^{\circledast}$ supplies.

\section{References}

Coil JM, Tonzetich J (1985). Volatile sulphur production at healthy and diseased gingival crevice sites (abstract). J Dent Res 64:306.

Dzink JL, Socransky SS, Haffajee AD (1988). The predominant cultivable microbiota of active and inactive lesions of destructive periodontal diseases. J Clin Periodontol 15:316-322.

Goldberg S, Kozlovsky A, Gordon D, Gelernter E, Sintov A, Rosenberg M (1994). Cadaverine as a putative component of oral malodor.J Dent Res (in press).

Laughon E, Syed SA, Loesche WJ (1982). API-ZYM system for identification of Bacteroides sp., Capnocytophaga sp. and spirochetes of oral origin.J Clin Microbiol 15:97-102.

Löe H, Silness J (1963). Periodontal disease in pregnancy. I. Prevalence and severity. Acta Odontol Scand 21:533-551.

Loesche WJ (1986). The identification of bacteria associated with periodontal disease and dental caries by enzymatic activity methods. Oral Microbiol Immunol 1:65-70.

Loesche WJ, Syed SA, Schmidt EC, Morrison EC (1985). Bacterial profiles of subgingival plaques in periodontitis. J Periodontol 56:447-456.

Loesche WJ, Syed SA, Stoll J (1987). Trypsin-like activity in subgingival plaque; a diagnostic marker for spirochetes and periodontal disease.JPeriodontol 58:266-273.

Loesche WJ, Bretz WA, Lopatin D, Stoll D, Rau CF, Hillenburg KL, et al. (1990a). Multi-center clinical evaluation of a chairside method for detecting certain periodontopathic bacteria in periodontal disease. J Periodontol 61:189-196.

Loesche WJ, Bretz WA, Kerchensteiner D, Stoll Y, Socransky SS, Hujoel $\mathrm{P}$, et al. (1990b). Development of a diagnostic test for anaerobic periodontal infections based on plaque hydrolysis of benzoyl-DLarginine-naphthylamin.J Clin Microbiol 28:1551-1559.

Mardinger O, Zubery Y, Kozlovsky A, Gelernter I, Tal I, Rosenberg M (1992). Volatile sulphide levels in periodontal pockets correlate with pocket depth (abstract). J Dent Res 71:1032.

Moore WEC, Holdeman LV, Cato EP, Smibert RM, Burmeister YA, Palcanis KG, et al. (1985). Comparative bacteriology of juvenile periodontitis. Infect Immun 48:507-519

Persson S, Edlund M-B, Claesson R, Carlsson J (1990). The formation of hydrogen sulfide and methyl mercaptan by oral bacteria. Oral Microbiol Immunol 5:195-201.

Rizzo AA (1967). The possible role of hydrogen sulfide in human periodontal disease. 1. Hydrogen sulfide production in periodontal pockets. Periodontics 5:233-236.

Rosenberg M, Gelernter I, Barki M, Bar-Ness R (1992). Day-long reduction of oral malodor by a two-phase oil:water mouthrinse as compared to chlorhexidine and placebo rinses.] Periodontol 63:39-43.

Rosenberg M, Kulkarni GV, Bosy A, McCulloch CAG (199la). Reproducibility and sensitivity of oral malodor measurements with a portable sulphide monitor.J Dent Res 70:1436-1400.

Rosenberg M, Septon I, Eli I, Brenner S, Gelernter I, Gabbay J (199lb). Halitosis measurement by an industrial sulphide monitor. J Periodontol 62:487-489.

Rosenberg M, McCulloch CAG (1992). Measurement of oral malodor: current methods and future prospects. J Periodontol 63:776-782.

Schmidt EF, Bretz WA, Hutchinson RA, Loesche WJ (1988). Correlation of the hydrolysis of benzoyl-arginine naphthylamine (BANA) by plaque and clinical parameters and subgingival levels of spirochetes in periodontal patients. J Dent Res 67:1505-1509.

Schmidt NF, Missan SR, Tarbet WJ, Cooper AD (1978). The correlation between organoleptic mouth-odor ratings and levels of volatile sulf ur compounds. Oral Surg Oral Med Oral Pathol 45:560-567.

Silness J, Löe H (1964). Periodontal disease in pregnancy. II. Correlation between oral hygiene and periodontal condition. Acta Odontol Scand 24:747-759.

Simonson LG, Goodman CH, Bial YY, Morton HE (1988). Quantitative relationship of Treponema denticola to severity of periodontal disease. Infect Immun 56:726-728.

Tanner ACR, Strzempko MN, Belsky CA, McKinley GA (1985). APIZym and API-ANADENT reactions of fastidious Gramnegative species.J Clin Microbiol 22:333-335. 
Tonzetich J (1971). Direct gas chromatographic analysis of sulphur compounds in mouth air in man. Arch Oral Biol 16:587-597.

Tonzetich J (1973). Oral malodour: an indicator of health status and oral cleanliness. Int Dent J 28:309-319.

Tonzetich J (1977). Production and origin of oral malodour: A review of mechanisms and methods of analysis. J Periodont 48:13-20.

Tonzetich J, Kestenbaum RC (1969). Odor production by human salivary fraction and plaque. Arch Oral Biol 14:815-827.

Tonzetich J, McBride BC (1981). Characterization of volatile sulphur production by pathogenic strains of oral bacteroides. Arch Oral Biol 26:963-969.

Tonzetich J, Ng SK (1976). Reduction of malodor by oral cleansing procedures. Oral Surg Oral Med Oral Pathol 42:172-181.

Tonzetich J, Richter VJ (1964). Evaluation of volatile odoriferous components of saliva. Arch Oral Biol 9:39-45.

Yaegaki K, Sanada K (1992). Volatile sulf ur compounds in mouth air from clinically healthy subjects and patients with periodontal disease. J Periodont Res 27:233-238. 